\title{
$\bigcirc$ A STUDY OF EL2 PILOTS' RADIO COMMUNICATION IN THE GENERAL AVIATION ENVIRONMENT
}

Dominique Estival, University of Sydney

Dr Dominique Estival received a PhD in Linguistics from the University of Pennsylvania and has research experience in Natural Language Processing both in industry and in academia. Her research interests have included the computational modelling of language change, machine translation, grammar formalisms, grammar development and linguistic engineering, and spoken dialogue systems. Dominique holds a Commercial Pilot License and a Flight Instructor Rating. Correspondence to Dominique Estival: Dominique.Estival@usyd.edu.au Brett Molesworth, University of New South Wales

Dr Brett Molesworth is a Human Factors and Aviation Safety lecturer with the Department of Aviation - UNSW. Brett's qualifications include a Bachelor of Aviation (Hons) and a PhD (UWS) where he examined individuals' propensity towards risk-taking. Brett is also a registered Psychologist with the NSW Psychologist Registration Board and holds a Commercial Pilot Licence, as well as an advanced aerobatics rating. Brett's research interests involve human performance in complex socio-technical environments with a passion for understanding the factors that influence individuals' 'at-risk' behaviour (risk management). Correspondence to Brett Molesworth: b.molesworth@unsw.edu.au

This paper reports on the preliminary stages of a project designed to investigate communication problems in General Aviation and assess the utility of language technologies as a means of mitigation. The study presented in this paper is the first of a three-part study, in which we aim to investigate the extent to which the English language proficiency of pilots whose native language is not English (EL2) impacts on their ability to effectively communicate with Air Traffic Control (ATC), and its potential impact on safety outcomes. In a preliminary survey, we distributed a questionnaire to General Aviation pilots at various flight training organisations and collected self-reported instances of miscommunication between themselves and ATC. In addition, we asked pilots to rank, in order of difficulty, five typical radio communication tasks. The results indicated that pilots who are English native speakers and EL2 pilots give a similar ranking of difficulty to the radio communicative tasks, and that both EL2 and native speakers rank understanding other pilots as the most challenging task. 


\section{INTRODUCTION}

This paper reports on the preliminary stages of a project designed to investigate communication problems in General Aviation and assess the utility of language technologies as a means of mitigation. While the overall goal of the project is to improve communication within General Aviation, we focus more specifically on eliminating or at least reducing miscommunications and misunderstandings between Air Traffic Control (ATC) and pilots whose first language is not English (EL2 pilots). The study presented compares radio communication problems reported by both English native speakers (NS) and EL2 pilots.

Proficiency with the English language has been identified as an integral part of international aviation safety (MacBurnie, 2004). As such, the international aviation governing body, the International Civil Aviation Organization (ICAO), has mandated that all new pilots and ATC personnel pass an English language proficiency test prior to obtaining their qualifications. This rule came into effect in Australia on 5 March 2009. While this move is extremely positive for safety within aviation, in practice there appears to be a number of teething problems (Alderson and Horak, 2009). Many training organisations seem to focus on training pilots to use Standard English, as well as some aviation-specific phraseology and jargon. Although the teaching of standard conversational English does include using pauses in appropriate places, as well as intonation to emphasise important or relevant information, these non-verbal features are not used by ATC in the way they are in normal conversation. In fact, the lack of intonation, rhythm and pauses which are typical of rapid radio communication in the aviation environment are known to be particularly problematic since no visual cues are present (McMillan, 1998; Prinzo, 2008). Thus, we want to suggest that the issue is in fact just as much a comprehension problem which involves both ATC and pilots as a language production problem for EL2 speakers. As a result, the present study (part one of a three part study) was designed to investigate the extent to which the English language proficiency of EL2 pilots impacts on their effective radio communication.

There have been many aviation accidents where (mis)communication is known to have been a factor (Cushing, 1994). This is one of the reasons why communication in the aviation environment is so highly coded and scripted and why a number of researchers have looked at particular aspects of aviation communication, from Charlotte Linde (USA) on the 'Linguistic Analysis of Aviation Accidents' (Goguen and Linde 1983; Linde 1988) to Maurice Nevile (Australia) on 'communication in the cockpit' (Nevile and Walker 2005; Nevile, 2001, 2005, 2006, 2007, 2008). 
Earlier studies of communication in the aviation environment have shown that prosody (intonation, stress and rhythm) plays an important role in radio communication. McMillan (1998) found that speed of delivery and (lack of) pauses were a significant cause of readback errors and that 'The rapid speed at which controllers deliver instructions is probably the most common miscommunication complaint received from pilots' (McMillan, 1998, p.46). Prinzo (2008) also found that readback errors were more common when ATC communications were complex and not broken into segments. Nevile (2008) shows that timing, silence and intonation are always crucial in verbal communication and that in the cockpit they can help distinguish 'clearances' from 'checking questions' (e.g., 'Cleared to land.' vs 'Cleared to land?').

In a number of aviation accident cases, miscommunication is known to be due in part to EL2, for instance in "Avianca 1990" (Helmreich, 1994), "Tenerife 1977" (Cushing, 1994) and more recently "Brazil 2006" (Oliveira, 2007). This has led to the new language proficiency standards developed by the ICAO. 'Following a series of highly publicised air accidents, ICAO responded to a request from its member states to investigate the potential causes. It was found that in several cases an inadequate knowledge of English could have been a contributing factor in the accident' (Emery and Roberts, 2008).

An important question for instructors, teachers and test examiners is the extent to which Standard English is required or whether a subset, "Aviation English", is more appropriate. This is one of the major topics discussed on the "flightenglish" list, with debates as to how much naturalness is needed in a crisis situation or what the requirement for aeronautical experience and technical knowledge should be for Aviation English teachers.

Mell (n.d.) gives an analysis of the use of English in an EL2 aviation environment and shows that spontaneous unscripted native English is not appropriate in such a context. In Mell's study, French trainee air traffic controllers were played a recording of a radio transmission where a British pilot became lost in French airspace and used non-standard spontaneous English. None of the trainee air traffic controllers were able to understand the British pilot's transmission. Conversely, Drury and Ma (2002) found that 'the use of other than a native language was an important causal factor in [these] errors' and that 'native English speakers should be taught how to communicate simply, slowly and precisely with their non-native English speaking colleagues'. Sullivan and Girginer (2002) also found significant variations in the use of English, even in the restricted aviation context of Turkish ATC-pilot communications. 
Farris et al. (2008) report on experiments to measure proficiency in EL2 for pilots under different workload levels. They found that the low-level EL2 proficiency group repeated messages less accurately and that their speech was perceived as more accented in the high workload condition. Although the experiments were conducted with nonpilot subjects and with tasks which do not adequately simulate flying situations, the structure of the experiments, with two levels of EL2 proficiency and two levels of workload, can be used as a starting point to design similar sets of experiments.

Communication problems within aviation are further compounded by the reliance on and need for radio transmissions, which result in a degraded speech signal. Moreover, the cockpit is a noisy environment and the presence of noise makes it more difficult for EL2 listeners to understand speech (Gat and Keith, 1978). For instance, Shimizu et al. (2002) report that in a study with native Japanese speakers (EL2), as the signal to noise ratio increased (white, pink and aircraft noise), the Japanese listeners found it much harder to discriminate between different English phonemes. According to Mayo et al. (1997) the difficulty in discriminating between English phonemes for non-native speakers is off-set with years of exposure to English, but never reaches the level of native speakers.

\section{RESEARCH HYPOTHESIS AND GOALS}

The underlying hypothesis for the research is indeed that EL2 pilots communicate less effectively with ATC and that ATC messages to EL2 pilots are harder for them to understand, even with high EL2 ability. Australian pilot training organisations with overseas students have long been aware of the problems caused by accents or dialectal differences as well as by the conversational use or interpretation of aviation terminology. ATC is also sensitive to the problems of foreign pilots speaking English, but may still sometimes use the colloquial meaning, for instance confirm to correct an incorrect readback. ${ }^{1}$

The busy training environment at some General Aviation aerodromes is very challenging for both pilots and ATC and provides numerous examples of communication problems and pilot errors due to misunderstandings. The series of accidents and incidents which have occurred in this environment over the past few years has led to the Review of the Utility to Australian airspace management of General Aviation Airport Procedures (GAAP) undertaken by CASA in 2009. One of the early findings (CASA, 2009, p.19) identified as an issue:

VI. Students with English as a second language struggle with radio calls - particularly if they are flying solo. 
While the assumption behind the ICAO regulations mandating English proficiency testing for pilots and ATC is that pilots need training in using English, we suggest that the issue is as much a comprehension problem involving both ATC and pilots, and that ATC also need to have an awareness and understanding of the challenges and difficulties EL2 pilots face in using English as a second language. It is therefore proposed that difficulties in ATC-pilot communication could be alleviated if both ATC and EL2 pilots could be made aware of potential communication problems. For example, intonation, rhythm and pauses are particularly problematic for radio communication but do not seem to be adequately addressed in the proficiency tests.

The whole project aims to focus on pilot-ATC communication (both standard and unusual) and the communication problems experienced by EL2 pilots, with four main objectives. First, we examine the extent to which English language proficiency actually impacts on effective communication as well as safety, with the aim to identify the causes of misunderstandings between EL2 pilots and ATC. Specifically focusing on investigating the contribution of linguistic factors such as intonation, pauses and stress, as well as unusual phraseology (e.g. 'The Smoke', referring to Sydney in an ATC clearance for a flight to Sydney) to such misunderstandings. Second, we will conduct experiments to identify particular areas of communication breakdown, examining the prevalence of communication breakdowns with EL2 pilots of different proficiency levels and under different workloads, in order to assess both accuracy of interpretation (comprehension) and ability to repeat phrases (repetition). Thirdly, we plan to develop and test training material to improve EL2 pilots' English proficiency in the areas identified as contributing to potential misunderstandings.

Finally, we will propose solutions to mitigate the problems identified. One type of solution could involve teaching a more effective communication strategy to ATC, e.g. pausing between transmissions to different aircraft, as well as to EL2 pilots, without affecting NS pilots or increasing the workload of ATC. In addition, we intend to develop a computer-based training tool (CECA - Clear and Effective Communication in Aviation) to help EL2 pilots and ATC recognise communications which are potentially difficult for EL2 pilots. Building from the CECA training tool, an automated tool can then be developed to identify potentially unclear or confusing messages. Clearly, such a tool needs to be helpful and not intrusive to ATC, i.e. not increase their workload but fit in to their workflow. 


\section{PILOT STUDY}

The pilot study presented in this paper was conducted in part one of the project described above. In this task, we aim to examine the extent to which the English language proficiency of EL2 pilots impacts their ability to effectively communicate with ATC. Before conducting focus groups to identify potential sources of communication problems (for instance, intonation, pauses or lack of pauses, rhythm, emphasis, and unusual phraseology), we conducted a survey to identify the extent of radio communication problems and the stages of flight in which they are most prevalent.

\section{QUESTIONNAIRE}

The survey questionnaire was designed to elicit information about the pilots' level of English proficiency and their level of training, as well as self-reports of radio communication problems they might have experienced. For flight training, there was a choice of five levels: Pre-solo, Solo, General Flying Progress Test (GFPT), Private Pilot Licence (PPL) and Commercial Pilot Licence (CPL).

The question about native language was phrased as 'Is your first language Australian English?' in order to distinguish between pilots coming from countries where different varieties of English are spoken. Some of these varieties (e.g. Indian or Singaporean English) are considered 'foreign' by Australian pilots because of the accent, even though the speakers may consider themselves as native speakers of English. A subsidiary question asked non-native speakers of English to identify their native language.

The next two sets of questions asked whether the pilot had 'ever been in a situation where you did not fully understand what ATC was telling you' and whether the pilot had 'ever been in a situation where ATC asked you to repeat what you said'. For each of these questions, subsidiary questions asked whether there had been a request for repetition and whether the repetition was more successful; what the message had been; and the stage of flight in which the communication problem had occurred. The choices of flight stages were: Circuit, Departure, Approach, or Nav[igation].

"The next question asked the pilots to rank the difficulty of five radio communication

tasks: 'Remembering what you have to say', 'Saying what you have to say', 'Understanding ATC', 'Understanding other pilots' and 'Reading back'”.

Finally, the last question asked whether the pilot had 'ever been in a situation where a problem with radio communication (not including radio malfunction or failure) resulted in an incident or a potential incident' and, if so, to give a brief description. 
After permission was obtained from the Chief Flying Instructors, paper copies of the questionnaire were left at various flying training institutions located at Bankstown airport (NSW, Australia), where student pilots and pilots of all levels were encouraged to participate in the survey. The survey was completely voluntary and anonymous, with the questionnaires returned in a sealed box collected by the authors several days later.

\section{RESPONDENTS}

Thirty-six pilots from these flight training institutions completed the survey. The mean flight experience of the pilots was 342 hours (range 15-2,800). Twelve of the pilots held a Private Pilot Licence, while eleven held a Commercial Pilot Licence. The remainder of the pilots had passed the General Flying Progress Test or were undergoing training to obtain this licence (Pre-solo and Solo stages of training) (see Table 1).

Nine language backgrounds were represented. Twenty-four pilots reported English as their first language, either Australian (23) or British English (1). The non-native speakers of English identified their native language as follows: four pilots reported Tamil as their first language, three Cantonese, two Malaysian [sic], one Malayalam, one Telugu, one Urdu and one Korean. On average, they reported having spoken English for 14 years (range 2-25).

\begin{tabular}{|l|c|c|c|}
\hline Training Level & \# of Participants & Mean Flight Hours & EL2 \\
\hline Pre-Solo & 2 & $15^{*}$ & 2 \\
Solo & 5 & $48^{*}$ & 4 \\
GFPT & 5 & 53 & 2 \\
PPL & 12 & $222^{*}$ & 3 \\
CPL & 11 & $701^{*}$ & 1 \\
Total & $35^{*}$ & 342 & $12^{*}$ \\
\hline
\end{tabular}

Table 1 Number of pilots distributed across flight training level, flying experience, and whether English is second language

("**" indicates that some respondents did not answer the question)

\section{RESULTS}

\section{CHALLENGES IN RADIO COMMUNICATION}

Since the main goal of the research was to examine what pilots find most challenging in aviation communication, and specifically whether any differences existed between NS 
and EL2 pilots, they were asked to rank in order of difficulty five common aviation communication tasks (see Questionnaire section above).

Eleven pilots reported the most challenging component of radio communication to be 'Understanding other pilots'. This was closely followed by 'Remembering what you have to say', which was noted by nine pilots as the most challenging component of radio communication. Five reported 'Reading back', two reported 'Understanding ATC' and a further two considered 'Saying what you have to say' the most challenging component of radio communication. Many pilots, whether native speakers of English or not, had problems answering the ranking question as formulated (with 1 being most difficult and 5 being least difficult). To ensure data accuracy, the 13 respondents who committed one or more errors (out of a possible five) in filling out this part of the questionnaire were excluded from the analyses presented below.

Based on the above distribution, a series of planned Wilcoxon Signed-Rank Tests were employed to examine the order in which pilots ranked, in terms of difficulty, these five aviation communication tasks. The Wilcoxon test is the non-parametric equivalent of the dependent-samples t-test and it was used since the data violated the assumptions underpinning parametric tests (i.e., small sample sizes and homogeneity of variance). With alpha set at .05, the median rank for 'Remembering what you have to say' (Mdn $=2.57$, Range $=4)$ was significantly higher than 'Understanding ATC' $(\mathrm{Mdn}=3.71$, Range $=4), \mathrm{z}(\mathrm{N}=21)=1.99, p=.047, r^{2}=.19$; the median rank for 'Understanding other pilots' ( $\mathrm{Mdn}=1.95$, Range $=3$ ) was significantly higher than 'Understanding ATC' $(\mathrm{Mdn}=3.71$, Range $=4), z(N=21)=3.69, \mathrm{p}=.000, r^{2}=.65$; and the median rank for 'Remembering what you have to say' $(\mathrm{Mdn}=2.57$, Range $=4)$ was also significantly higher than 'Saying what you have to say' $(\mathrm{Mdn}=3.62$, Range $=4), \mathrm{z}(\mathrm{N}=21)=2.28$, $\mathrm{p}=.023, r^{2}=.25$.

Based on the above analysis, 'Understanding other pilots' ( $\mathrm{Mdn}=1.95$, Range $=3$ ) was found to be the most difficult, followed by 'Remembering what you have to say' $(\mathrm{Mdn}=2.57$, Range $=4)$, 'Reading back' $(\mathrm{Mdn}=3.14$, Range $=4)$, 'Saying what you have to say' ( $\mathrm{Mdn}=3.62$, Range $=4$ ), with 'Understanding ATC' ( $\mathrm{Mdn}=3.71$, Range $=4)$ as the least difficult.

In summary, if the tasks were to be ranked, the order would be as follows, with number 1 being the task pilots found most challenging in radio communication.

1. Understanding other pilots,

2. Remembering what you have to say,

3. Reading back, 
4. Saying what you have to say,

5. Understanding ATC.

\section{NATIVE LANGUAGE AND TASK DIFFICULTY}

In order to determine if the differences observed with task difficulty could be explained by native language, a one-way analysis of variance (ANOVA) was employed. Since the data violated the assumptions underpinning parametric tests (i.e., homogeneity of variance), a Kruskal-Wallis non-parametric test was used. With alpha set at .05 , the results failed to reveal any statistically significant differences, $X^{2}(5,21)=3.77, p=.58$. This result suggests that native language was not an influencing factor in what pilots found difficult with radio communication.

\section{LICENCE TYPE AND TASK DIFFICULTY}

In order to determine if the differences observed with task difficulty could be explained by pilot qualifications (level of training), a Kruskal-Wallis non-parametric test was employed. Consistent with the previous analysis, a one-way ANOVA alternate (KruskalWallis test) was employed since the data violated the assumptions underpinning parametric tests. With alpha set at .05 the results failed to reveal any statistical significant differences, $X^{2}(3,20)=5.77, p=.12$. This result suggests that qualification had no impact on which radio communication task pilots found most difficult.

Pilots were also asked to suggest other areas of difficulty in radio communication. Only three answers were given to that question, and all three mentioned EL2 pilots:

(\#1) 'pilots whose first language is not English'

(\#20) 'it's very hard when pilot is mumbling/broken english' (sic)

(\#36) 'Bloody Indians' [sic]

These answers point to the widely held belief in the aviation community, especially around busy training airports, that EL2 pilots cause communication problems.

\section{PILOTS UNDERSTANDING ATC}

In order to better understand the challenges pilots face when communicating with ATC, a series of questions were asked about this interaction. The first question asked whether pilots had been in a situation where ATC did not fully understand their message. Specifically the question read: 'Have you ever been in a situation where you did not fully understand what ATC was telling you'. Twenty-one pilots answered that they had. Fourteen 
of these pilots reported English as their first language; two reported Cantonese, two Tamil, two Malaysian, and one Korean. No Malayalam, Telugu, or Urdu native speakers reported such an event. One pilot (\#25) who failed to understand the message did not ask ATC to repeat, noting that the instructor had clarified the message. The other twenty pilots asked ATC to repeat the message and all but two pilots understood the message the second time. One of these (\#5) was able to report exactly what the message had been, while the other (\#9) did not answer the question.

From the fifteen pilots who reported what the message had been, four noted that it related to clearance (route or altitude), four to runway direction change, and one each for the following: aircraft call-sign, navigation instruction, breach of controlled airspace, and radio interference. The majority of the instances where the pilots requested ATC to repeat the instructions occurred in close proximity to an airport. Seven of the twentytwo reported instances occurred in the circuit, nine when approaching to land, four during navigation, one on departure, and one unspecified.

\section{ATC UNDERSTANDING PILOTS}

To gain a better understanding of the situation and factors surrounding those circumstances where pilots had been asked by ATC to repeat their transmission, pilots were first asked to report if they had experienced such a situation. Specifically pilots were asked: 'Have you ever been in a situation where ATC asked you to repeat what you said?' Twenty-six pilots reported that they had. Seventeen identified English as their native language, three Cantonese, two Malaysian, two Tamil, one Malayalam, and one Korean. No Urdu or Telugu native speakers reported such an occurrence. All but one pilot reported that ATC understood the message the second time. The vast majority of the messages pilots were trying to transmit related to aircraft call-signs (10), followed by clearance information (7). There was one upwind call (i.e. shortly after take-off), one regarding flight information, and one due to radio transmission interference, while three of the respondents did not identify what the message had been. Similar to the situations where pilots failed to understand instructions from ATC, ATC failed to understand pilots mostly during approach (9), during circuits (6), upon departure (5) and during navigation (6).

Only two pilots answered the last question and gave a narrative report on an incident. Unfortunately, even though the question specifically excluded problems of radio malfunction, one (\#6) reported an incident which was in fact due to a radio problem rather than a communication problem. The other (\#36) gave a specific example of an incident where two EL2 pilots, designated as 'Indians', could not be understood by other pilots on ap- 
proach at a regional airport. Note that this is the same pilot (\#36) who used the phrase 'Bloody Indians' in answer to the previous question. This derogatory phrase is often used to refer to overseas student pilots and this prejudice against Indian student pilots unfortunately appears to be very strong in the Australian General Aviation community (and, as recent events have shown, it seems to be reflected in the wider community).

\section{DISCUSSION}

English has become the accepted international language in aviation, but only recently has the international governing body introduced a proficiency test for all pilots and air traffic control personnel to ensure a base level of English is achieved. This requirement can only be positive from a safety perspective. However in practice, anecdotal evidence suggests that the standard of English deemed proficient by the governing body may not be adequate. Therefore the main aim of the present research was to investigate the extent of communication problems within General Aviation and whether a solution or a number of solutions could be proposed to improve the situation.

The results of this preliminary study appear to support the notion that the use of English as a second language may contribute to communication difficulties in General Aviation. However, there is limited evidence from the present research to suggest that EL2 pilots are the primary source of communication problems. Both native English speaking pilots and EL2 pilots find it difficult to understand other pilots and both experience the same problems communicating with ATC. This result suggests that other factors contribute to this problem (e.g., noise and operator expectation).

In an attempt to further understand the situation, a Kruskal-Wallis non-parametric analysis was performed to determine whether, as pilots progress through their flying career, the problem of understanding other pilots increases or whether another challenge within aviation takes priority. The results suggest that neither is the case. Moreover, the challenge of communicating with other pilots appears to be universal across licence types.

Having demonstrated that communicating with other pilots is a challenge, the descriptive results suggest that the task of communicating with ATC also poses a problem. Moreover, irrespective of native language, only a minority of pilots denied having ever needed to ask ATC to repeat a transmission. This suggests that the causes of communication problems are not limited to native language and confirms that communicating over the radio is at the best of times difficult, irrespective of profession (pilot or ATC) or language background. It is important to note however that the actual frequency of communication problems was not ascertained in this study. 
Similarly, pilots from most backgrounds reported that they had been asked to repeat a message from ATC. As with the question about asking ATC to repeat the message, no data relating to frequency of occurrence was collected. Nonetheless, this result also suggests that communication problems are not specific to either language background or pilot qualification.

As we would expect from the point of view of the theory of communication, cases of ATC not understanding pilots and of pilots not understanding ATC occur when the message is less predictable from the context. For ATC, these messages are aircraft call signs, which ATC cannot anticipate, and unusual or unexpected clearance requests from pilots, either on departure or arrival. For pilots, unexpected messages from ATC are clearances, instructions, information about runway direction changes, and (presumably unanticipated) information about having breached controlled airspace or about conflicting traffic.

In summary, the results of the present research suggest that effective communication within General Aviation is challenging and that pilots of all backgrounds and qualification levels experience communication difficulties. It is well known that a number of factors, apart from native language, contribute to communication problems. For example, noise (Shimizu et al., 2002), operator's (pilots and ATC) expectation (Cushing, 1994; Hutchins and Klausen, 1996) as well as communication or English language standards (Helmreich, 1994). However, in view of the perception that EL2 pilots are a threat to General Aviation safety, it is the latter of these factors which is of particular interest to the present research.

\section{LIMITATIONS AND FUTURE RESEARCH}

While the results of the present study help identify key communication problems within General Aviation, they need to be interpreted with a level of caution. As noted above, the present research is a preliminary study into communication problems within aviation, and this is reflected by the sample size for the survey. Future research should build on these findings with a more substantial sample base, expanding participant numbers from all demographics, i.e., NS pilots and EL2 pilots from a variety of language backgrounds, as well as more pilots with different levels of training.

As we expected, even though the survey was anonymous, pilots seem to be reluctant to report difficulties in flight which may have led to an incident or a potential incident. It is extremely unlikely that so many pilots ( 15 out of 36 ) never had to ask ATC to repeat a message, or that they were never asked by ATC to repeat something, if only their call sign ( 10 out of 36 denied having been asked to repeat a message). Any pilot knows that 
this is a frequent occurrence and not in itself a cause for concern. Thus it may be necessary to modify the way the questions are asked, so that the emphasis is not on whether such incidents occur, but when they do occur.

Importantly, future research should be directed towards investigating the frequency of such occurrences in order to prioritise means of mitigating communication problems. In addition, future research should be more precise about the details/factors surrounding communication problems, for instance, distinguishing between 'Approach to land' and 'Approaching an airfield or a terminal area', i.e. during a navigation flight. Finally, while pauses, intonation, stress and rhythm have been identified as factors contributing to communication difficulties (McMillan, 1998; Prinzo 2008), future research should not be limited by these findings -- in other words, be inclusive not exclusive.

The larger project aims to investigate communication problems in the aviation environment, more specifically between ATC and EL2 pilots. Although current practice and legislation mandate pilot training in English, difficulties in ATC-pilot communication might also arise from comprehension errors which could be alleviated if ATC was aware of EL2 communication problems. The preliminary survey collected self-reported instances of miscommunication potentially impacting on flight safety. We are planning experiments to investigate what misunderstandings actually occur and to identify the contribution of intonation, pauses and stress, as well as unusual phraseology. The full project will propose solutions based on 1) teaching better communication strategies to ATC (e.g. pausing between transmissions to different aircraft), and 2) technical solutions to identify potentially unclear or confusing messages.

The immediate benefits of improving radio communication within General Aviation are twofold: a reduction in radio transmissions traffic and a reduction in incidents from miscommunication, both of which can only be positive for the aviation industry.

\section{CONCLUSIONS}

The results of this pilot study suggest that communication problems pose a threat to General Aviation safety. Specifically, what emerged from this study is that the most challenging communication problem for pilots is not with ATC, but with other pilots, and that, irrespective of qualification or native language, pilots find it most difficult to understand other pilots. In contrast, pilots found communicating with ATC to be the least challenging of the five communication tasks. This result indicates that communication problems within General Aviation cannot be solely attributed to language proficiency levels of EL2 pilots. Rather, the problem appears to be more widely spread and the results 
suggest that all pilots experience, and contribute to, communication problems within General Aviation. There is also evidence that, consistent with other research, expectation of receiving a particular instruction or message is a contributing factor. Given the outcomes of the present study, future research should be directed towards investigating the components of effective communication within General Aviation with the intent to suggest improvements to present language proficiency requirements.

\section{ACKNOWLEDGEMENTS}

We wish to thank our colleagues, Robert Dale, Mark Wiggins and Tim McNamara for their input to the research proposal which was submitted to the Civil Aviation Safety Authority Research Committee, and Roger Weeks and Kerry Nolan from the CASA Flight Training and Testing Centre for their comments on an early draft of that proposal. We also thank the flying training organisations at Bankstown which helped us collect the data for this pilot study.

\section{ENDNOTES}

As shown by the following example provided by an ATC instructor (McMillan, p.c., with permission):

"Most controllers are sensitive to the problems of foreign pilots speaking English. Sometimes they don't appreciate how narrow the understanding of the language is, though.

"An example I use in class occurred when I was training another controller. The word 'confirm' has a specific meaning in AIP, to query something, such as 'confirm climbing to flight level two zero zero'. However some Australian controllers, and pilots, [mis] use it more colloquially to correct an incorrect readback:

"My trainee said to a Thai pilot 'descend to flight level two nine zero'.

“The pilot read back, 'descend to flight level two five zero'.

"To which the trainee responded, 'confirm flight level two nine zero'.

"There was a short silence, perhaps the pilots were conferring with each other, then a response, 'what is it that you want me to confirm?'.

"Quite a few errors here: the trainee should have said 'niner', and responded with 'negative, descend to flight level two niner zero'. And it highlights the very specific understanding that a foreign pilot has of particular words.” 


\section{REFERENCES}

Alderson, J. Charles; Horák, Tania (2009). Report on a Survey of National Civil Aviation Authorities' Plans for Implementation of ICAO Language Proficiency Requirements. Report prepared for the ICAO. Lancaster University.

CASA. (2009). Airspace Review of Bathurst Aerodrome. Unpublished report, March 2009. Canberra: Civil Aviation Safety Authority. Available from:

http://www.casa.gov.au/scripts/nc.dll?WCMS:STANDARD:1001:pc=PC_90447.

Cushing, Steven (1994). Fatal Words: Communication Clashes and Aircraft Crashes. Chicago: University of Chicago Press.

Drury, Colin G.; Ma, Jiao (2002). Language Error Analysis - Report on Literature of Aviation Language Errors and Analysis of Error Databases. Report prepared for the Federal Aviation Administration (FAA). University of Buffalo, State University of New York.

Emery, Henry; Roberts, Andy (2008). Aviation English for ICAO Compliance, Oxford: Macmillan.

Farris, Candace; Trofimovich, Pavel; Segalowitz, Norman; Gatbonton, Elizabeth (2008). Air traffic communication in a second language: Implications of cognitive factors for training and assessment. TESOL Quarterly, 42(3), 397-410.

Gat, Isabelle B; Keith, Robert W (1978). An effect of linguistic experience. Auditory word discrimination by native and non-native speakers of English. Audiology, 14(4), 339-345.

Goguen Joseph A.; Linde, Charlotte. (1983). Linguistic Methodology for the Analysis of Aviation Accidents. NASA Contract Report 3741. Washington, DC: National Aeronautics and Space Administration.

Helmreich, Robert L (1994). Anatomy of a system accident: The crash of Avianca Flight 052. International Journal of Aviation Psychology, 4(3), 265-284.

Hutchins, Edwin; Klausen, Tove 1996. Distributed cognition in an airline cockpit. In Engström, Y. and Middleton, D (Eds.), Cognition and Communication at Work (pp. 15-34). Cambridge: Cambridge University Press.

Linde, Charlotte (1988). Politeness and accidents in aviation discourse: The quantitative study of communicative success. Language in Society, 17(3), 375-399.

Mayo, Lynn Hansberry; Florentine, Mary; Buus, S (1997). Age of second-language acquisition and perception of speech in noise. Journal of Speech, Language and Hearing Research, 40(3), 686-693.

MacBurnie, Eric (2004). Aviation language proficiency. ICAO Journal, 59(1), 4-27.

McMillan, David (1998). “...Say again?...” Miscommunications in air traffic control. Unpublished master's thesis, Queensland University of Technology, Brisbane, Queensland, Australia.

Mell, Jeremy (n.d.). "Emergency Calls - Messages out of the blue". Toulouse: Ecole Nationale de l'Aviation Civile. Available from http://www.icao.int/anb/sg/pricesg/background/OotB.htm.

Nevile, Maurice. (2001). Understanding who's who in the airline cockpit: Pilots' pronominal choices and cockpit roles. In McHoul, A.; Rapley, M. (Eds.), How to Analyse Talk in Institutional Settings: A Casebook of Methods. London: Continuum. 
Nevile, Maurice (2005). "Checklist complete" Or is it? Closing a task in the airline cockpit. Australian Review of Applied Linguistics, 28(2), 60-76.

Nevile, Maurice (2006). Communication in Context: A Conversational Analysis Tool for Examining Recorded Voice Data in Investigations of Aviation Occurrences. Report prepared for the Australian Transport Safety Bureau. ATSB Research and Analysis Report B2005/0118.

Nevile, Maurice (2007). Action in time: Ensuring timeliness for collaborative work in the airline cockpit. Language in Society, 36(2), 233-257.

Nevile, Maurice (2008). Being out of order: Overlapping talk as evidence of trouble in airline pilots' work. In Bhatia, Vijay K.; Flowerdew, John; Jones, Rodney H. (Eds.), Advances in Discourse Studies. Abingdon, UK: Routledge.

Nevile Maurice; Walker, Michael (2005). A Context for Error: Using Conversational Analysis to Represent and Analyse Recorded Voice Data. Report prepared for the Australian Transport Safety Bureau. ATSB Aviation Research Report B2005/0108.

Oliveira, Kelly (2007, February). Command of English would have prevented Brazil's worst air tragedy ever. Brazzil Magazine. Available from http://www.brazzilmag.com.

Prinzo, O. Veronika. (2008). The computation and effects of air traffic control message complexity and message length on pilot readback performance. In Spink, A.J.; Ballintign, M.R; Bogers, N.D., Grieco, F.; Loijens, L.W.S.; Noldus, L.P.J.J; Smit, G., and Zimmerman, P.H. (Eds.), Proceedings of Measuring Behavior 2008 (Maastricht, The Netherlands, August 26-29, 2008).

Shimizu, Takashi; Makishima, Kazumi; Yoshida, Masafumi; Yamagishi, Hidetoshi (2002). Effect of background noise on perception of English speech for Japanese listeners. Auris Nasus Larynx, 29, 121-125.

Sullivan, Patricia; Girginer, Handan (2002). The use of discourse analysis to enhance ESP teacher knowledge: An example using aviation English. English for Specific Purposes 21(4), 397-404.

Cite this article as: Estival, Dominique; Molesworth, Brett. (2009). 'A study of EL2 pilots' radio communication in the General Aviation environment'. Australian Review of Applied Linguistics 32 (3), 24.1-24.16. DOI: 10.2104/aral0924. 